\title{
Siberian identity in the historical perspective and at present
}

\author{
Viacheslav Shevtsov $^{1, a}$, Iraida $\mathrm{Nam}^{1}$, and Elena Khakhalkina ${ }^{1}$ \\ ${ }^{1}$ Tomsk State University, 634050 Lenin Avenue, 36, Tomsk, Russia
}

\begin{abstract}
The "clever" technology for creation and applying a positive image of the region accompanied by the federal and local regional policy to enhance the attractiveness of Siberian territories should become the most important condition for maintaining of social stability in the region and a kind of a translation channel of mechanisms of social comparison in a constructive direction. The factor of common Siberian identity cannot be regarded as a threat to the stability of the foundations of the state, but as a way to preserve the balance of power in the region and as a necessary component of civic identity.
\end{abstract}

\section{Introduction}

A large area of the Russian Federation, its natural diversity and its position on the crossroads of different cultural worlds predetermined a formation complexity and the current state of Russian society. Migration of peoples, their intermingled settlement, a long process of state formation in the XV-XIX centuries and its territorial division at the end of the XX century were key factors in the spatial differentiation and regionalization of Russia. There are territorial regions as Pomerania, North, Volga, Ural, Primorye, Northern Caucasus, Siberia, etc. They are a special area with indistinct borders, but the existing management system, the environment, social and spiritual relations, historical past and mentality. The boundaries of such spaces, areas defined the sense of identity of the operating people in it, defining the norms of their behavior and perception. Knowledge and updating of the special mentality of the Regions is one of the foundations of civil society development, the factor of social and cultural unity of Russian society.

\section{Materials and methods}

The identity may be defined as the attribution of a set of real or imagined properties to the individual or a social group [1]. Analysis of identity is possible by identifying properties that allow describing the content of the identity; determining the identity of the structure elements which constitute it; establishment of functions that identity performs or can perform; recognizing the factors affecting the formation and transformation of identity. Regional identity arises in the community on the basis of already existing ethnic and religious and socio-corporate forms of self-identification. This involves understanding of the identity as the phenomenon of a dual nature, which is composed of the basic elements - relatively "constant" values, norms and ideas raised by membership to the particular social and cultural traditions and "responsible" for unambiguous perception of what is happening, and the elements of the "situational", arising under the influence of external factors. This makes the identification process uncompleted, and puts it in dependence on the internal consistency of basic and situational.

In describing regional identity it is necessary to use the definitions of system theory - the "core" and "periphery" and the approaches used by humanitarian geography. In this case, the "core" of regional identity became the notions of the territory of residence as "their" vesting its axiological properties, and the "periphery" became social practices, by means of which the sense of belonging to a certain territory is included in the overall identification scheme and interacts with other individual and group identity.

Functions that regional identity performs or may perform in culture or in relation to other forms of identification are the following:

a) The function of social or ideological orientation. The regional identity purpose is to indicate values, which should seek to residents particular territory; their justification of past or present social experience. In this case, regional identity can be the basis for the formation of a common civic identity, suggesting the existence and self-esteem of individuals and communities in general / single categories, leveling differences (Russian or Siberian), and in terms of a part / whole (Siberian as a component of Russian-ness) implying self-understanding as an essential element without which the integrity of the system is impossible.

b) The function of integration is manifested in the ability to rally the regional identity of individuals and

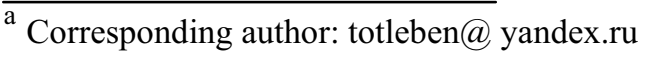


groups into a single entity - a social community, and through it - in the social system, thereby directing the actions of its members to achieve group goals.

c) The function of socialization (cultural, economic, etc.) - the process by which the external environment has a key influence on the formation of regional identities, causing them to be responsive to the social conditions, which are their part. For example, to accept or metabolize certain standards (European or Asian communities).

d) The identification function - ensuring the formation of a sense of belonging to a particular territory and hierarchy of this affiliation: I am a resident of the village, the city, the regional center, a specific area or the whole Siberia.

e) The compensation function - replenishment of failure in the implementation of the other identification options (failure of modernization can refocus on the revival of interest in regional traditions). In this case, regional identity is an important condition for cooling of claims by reorienting interests and ambitions of the nearby and more realistic goals.

g) The pragmatic function allows extracting dividends through the adoption of a model (tourism, credit, positive attitude, forces of influence) and accumulating capital (economic, social, cultural). Thereby, increasing the potential of the region for the formation of a positive image of their own - attractive to investors, the youth, necessary specialists, etc.

\section{Results and discussion}

Appealing to the problems of national and regional identity reoriented domestic Siberian studies seriously. Today it is recognized that the region is a unique research platform for the reconstruction of identity as a "second reality" due to its structural heterogeneity and ethnic diversity. Singled out as the main features of its special status of Siberian "separateness" and simultaneously "integration in the national space", researchers are trying to understand the origins of a sense of territorial isolation, the processes of building a special Russian-Siberian identity, the nature of the ambivalence of images of Siberia.

The process of joining Siberia to Russia, which began at the end of the XVI century, was a long, complex and highly controversial phenomenon in its consequences. Siberia, which became a single administrative unit only after the 1820 s, had "no history of independent political existence, nor claims to a separate ethnic identity, no clear boundaries" up to that time. Siberia, which Ermak conquered, generally speaking was a small Tatar Khanate on the Irtysh River; later - a narrow strip of the territory along the Chinese border (including northern Kazakhstan today)". [2] Becoming an integral part of Russian, Siberia still represents a special historical-geographical, political and administrative structure.

Modern Siberia is the region with "special" identity as a unique area where the area of 10 million square kilometers includes 19 subjects of the Russian
Federation, and which is built on a territorial and national-territorial basis. The population of Siberia is 24 million and it includes representatives of more than 100 ethnic groups. It is here where the main resource and commodity reserves of Russia are located, development of Siberian identity is determined by the multiethnic region, the multicast migration and historical events. It is remaining the present focal point of distribution of the population. Impossibility in these conditions to release officially the titular nations determines the landmark feature of the territorial component of the overall Siberian identity. It is based on ideas about specific places of residence and limits its manifestations in small communicative circles (family, professional group of friends) [3]. Besides, it did not attach particular importance to the confessional, ethnic and regional differences. This localization, on the one hand, determined by the processes of atomization, is characteristic today of the whole of Russian society. On the other hand, such localization, caused by the overall process of individualization and personal orientation, implemented typical of modern industrial societies. Such identity is purely functional in everyday life - a sense of "small country" supports cultural (genetic) memory of Siberian communities, determines the interest in local history, including the history of their own emergence in the region and relaxed attitude to other groups autochthonous and alien. This is the reason and the condition of the inside of the Siberian tolerance and stability. An implicit feature of this identification is its reliance not only on the components of rational, but on myths, memories, values and symbols, projecting very real factors in its construction and maintenance [4]. The increasing complexity of the modern world of social relations, the reality of multiculturalism, mobility and migration can contribute not only to rationalization of consciousness, but also to the amount of contact and a degree of interweaving of various social myths, memories and legends.

Today, it is often stated that the main economic resource of Siberia should be considered not the natural ones, but the intelligence and high technology, on the one hand, and the «Siberian nature» - independence, cultural lability and endurance, on the other. At the same time it is becoming increasingly clear that it is impossible to endlessly exploit the positive image of the part of Siberia - the scientific and technical potential in the region - as it is not the basis of its economic development. Similarly, it is with the «Siberian character » whose existence is as much an influential phenomenon contested - «character » is blurred by an active migration processes of the twentieth century. The gradual passing of the generations of people who can live in economic hardship and financial distress, the reluctance of most active and educated youth to link their future with Siberia also influence on the «Siberian character»".

This raises the legitimate question of how the federal center sees Siberia as a part of Russia, and not as a financial «burden» or source of raw material or intellectual resources. For a simple Siberian everyman it is still unclear why the population of Siberia and the Far 
East which has rich natural resources have not the same thr quality and standard of living as the people of Moscow and St. Petersburg. Such discussions do not cease, including due to a problem of distribution of federal funds among the regions, and the so-called tax on the extraction of minerals. So it is clear why in the $2000 \mathrm{~s}$ as a kind of reaction to the alignment of the « vertical of power» in Siberia and unequal relations «ctntreperiphery » newly delineated surge of interest atose to the ideas of the mid XIX century regionalists and their projects in the region of decentralization. But in reality, so called oblastniki (G. Potanin, N.M. Yadrintsev and others) urged not to secede Siberia from the rest of Russia, many have tried to draw the authorities' attention to the very problem of development of the region as an integral part of a single state. The theme of the progressive development of Siberia oblastniki develop critical polemical manner, but without any opposition to the central government. They pointed out that it is necessary to transfer those forms of social, cultural and economic life to Siberia, which already existed or were further developed in the capital and the central provinces.

Siberia is a unique "research platform" for resolving the issue about the nature of regional identity. On the one hand, Siberian today's identity is living in conditions of constant growth of social and economic tensions and because it example can be seen on the reality of the prospects federal separatism. On the other hand, the population of the region is socially and culturally heterogeneous. On its territory the cultures of different stages coexist: for example, there are traditional reindeer culture of northern areas and places of post-industrial culture of megacities (Krasnoyarsk, Novosibirsk, Omsk, Tomsk). No less important and socio-cultural gap between residents of large cities (for a few of the region) and the rural periphery, to which the standard of living should also include the small city of Siberia. Accordingly, by the example of the region we can try to determine how the stability of regional forms of identification joins the stable social positions of individuals.

Fig. 1. [5] The immigration level in Siberia per 1000

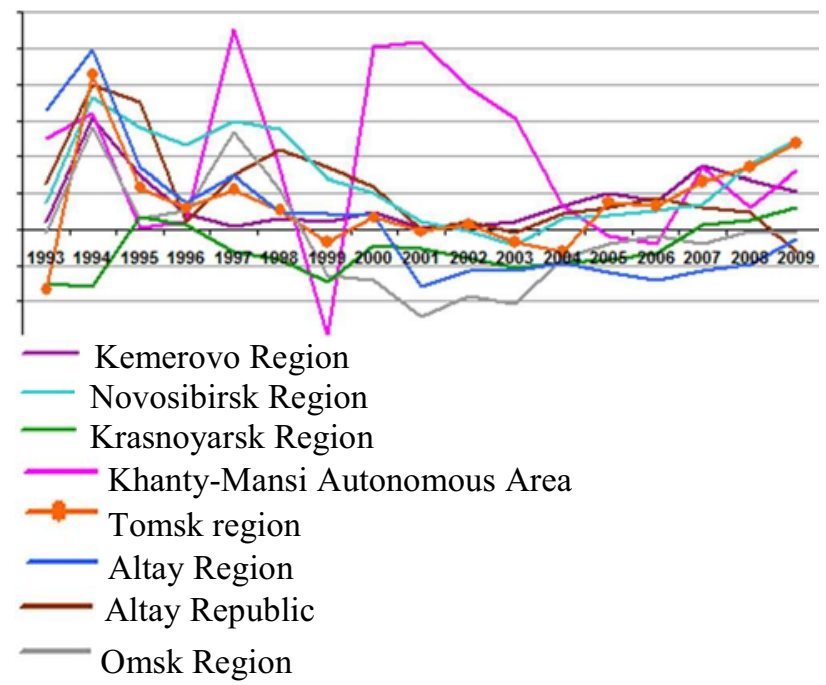

The migration outflow is typical for almost all of Eastern Siberia and the migration inflow zone was formed in the south of Western Siberia in the 1990s due to migration from the Commonwealth of Independent States (CIS countries). The influx from Central Asia has been the most intense in the first half of 1990, and from Kazakhstan it was intensive in 1996-1997. After the period of so named "stress migration" inflow dropped sharply, only the most economically prosperous KhantyMansiysk 3-4 years remained attractive for migrants (migration in the Khanty to the greatest extent due to economic factors).

Modern Siberia was involved into the globalization processes so that in some of its subregions the idea of formation of transnational identities arose on the ethnic or religious grounds (for example, the concept of "Big Altay" $[6,7])$. So the ethnic development and ethnocultural adaptation of diasporas is one of the most important areas of research in Russian ethnography and history. Following successive migrations in the late 19th and early 20th centuries6 several diasporas emerged in Western Siberia, and were forced to adapt to local conditions. The numerically predominant Russian population was the key factor in rapid and significant changes in the ethnic traditions of immigrants. Among the "new diaspora", rising since the end of the 20th century in connection with the collapse of the Soviet Union were the Armenian, Azerbaijani, Tajik, Uzbek and Turkmen. Nowadays the migration patterns are changing. A large scale economic and linguistic integration of the diasporas into the population structure of the region caused a leveling of ethnic differences and an erosion of ethnic identity, eventually resulting in voluntary assimilation [8]. Another factor significantly influencing the formation of regional identity is the growth of the population migrating to Siberia from the southern regions of the former Soviet Union, accompanied by the formation of a part of its population, together with the world, the "new" (contemporary) diaspora. The very formation of the "new diaspora" seriously complicates, diversifies the palette of the social structure of the population, especially of the urban part. The emergence of a new element inevitably breaks the previous balance, a habitual way of life that brings in new mechanisms for community development and new conflicts. [9]

Today, there was a significant breakthrough in the study of migration processes in the Russian historiography. We can say that a research tradition is forming, setting the important research tasks and methodology. The main focus of scientific interest is the analysis of the migratory flows and the assessment of the phenomenon from the point of view of national and common security for the Russian state and society. But knowledge of only quantitative indicators can not give an adequate understanding of the problem. We must move from the flow measurement to the analysis of the forms, methods and mechanisms of activity of migrants. We should take into account their adaptation to the host society and their life strategies and motivations and formed networks of their structure, genesis and 
functioning. In other words - to issue of forming of the migrants' diasporas.

Diaspora - is not granted, its existence (or nonexistence), the appearance and disappearance can be a situational response to the challenge of the times, places and circumstances. Based on this approach, the presence of the aggregate of persons of the same nationality living outside the homeland, even though numerous and rooted in their new homeland, is not the diaspora, but only a necessary condition for its implementation. In other words, the same people, the combination of these people may or may not present diaspora. Diaspora, communities, networks and relationships, built on this basis, can be and are a critical resource for economic success of migrants. They can be the instrument of their integration into the host society. Most often, however, they are considered as a factor counteracting such integration.

The revival of regional identity is a worldwide phenomenon, which is a reflection of modern globalization processes, actively taking place in European countries [10]. For further dynamic development of Siberia there is a problem of transition from the imperative of public thinking, formulated by the Russian scholar and lexicographer of the XVIII century, Mikhail Lomonosov: "The power of Russia will grow by Siberia ..." to ideologeme proclaimed by exiled Decembrists Gavriil Baten'kov "Siberia is a flywheel for moving of our immeasurable Fatherland and necessary feature of its Majesty".

\section{Conclusion}

In the context of modernization, globalization, innovation, the processes of "Siberian identity" and the ability to participate in the design of adaptive life strategies of its "media" are overly dependent on external factors, including a significant place occupied by federal government policy. It is the content and nature of the evaluation and it determines the perception of space Siberians own residence as a favorable or unfavorable to life. Sophisticated technology used to create and use a positive image of the region, along with federal and local regional policy meant to enhance the attractiveness of Siberian territories may become the most important conditions for maintaining social stability in the region, a kind of a translation channel social comparison mechanisms in a constructive direction. The factor of common Siberian identity cannot be regarded as a threat to the stability of the foundations of the state, but as a way to preserve the balance of power in the region and as a necessary component of civic identity.

In modern Russia relations « center-regions 》 - is not an idle question, on its timely and adequate resolving depends the future development of the country and its emergence as a respected public and the international community, power, and not a divided arbitrarily into "wealth center» and "poor regions ». The growing income gap, a gap in obtaining elite education, guaranteeing high wages and work in prestigious companies, and achieving a high standard of living dictates mentality difference and according assesses of the Kremlin's actions on the part of the center and regions. These processes have led and lead to increased dissatisfaction with Moscow's policy in the region, not fraught with difficulties but impossibility of appearance of a unifying national idea and, as a consequence, forming all-Russian identity and civil society.

\section{Acknowledgment}

This article is prepared as part of the research work in the scientific center of Transsiberian Scientific Way (TSSW), Tomsk State University, with financial support of the project «Man in a Changing World. Problems of identity and social adaptation in history and at present» (RF Government grant П 220 No. 14.B25.31.0009).

\section{References}

1. B. Anderson, Imagined communities, reflections on the origin and spread of nationalism (Verso, London, N.Y., 1991)

2. Between Heaven and Hell. The Myth of Siberia in Russian Culture. Ed. by G. Diment and Y. Slezkine (N.Y., 1993)

3. E. Dutchak, V. Kashpur, Obshchestvennye nauki i sovremennost', 4, (2013)

A. Makarychev, Neprikosnovennyy zapas, 3 (2010)

4. Resource: Independent Institute for Social Policy. Social Atlas of Russian Regions. Tomsk region http://atlas.socpol.ru/portraits/tomsk.shtml

5. Eurasia: Regional perspectives (Siberian Scientific Publishing House, Novosibirsk, 2007)

6. G.A. Aksyanova, Archaeology, Ethnology and Anthropology of Eurasia, 39 (2), (2011)

7. D.G. Korovushkin, Archaeology, Ethnology and Anthropology of Eurasia, 37 (1), (2009)

8. V. Dyatlov, Migration, migrants, the "new diaspora": a factor of stability and conflict in the region, Baikal Siberia: what constitutes stability? (Natalis Publishing, Irkutsk, 2005)

9. Logos, 6, (2003) 